\title{
Long-term response of over ten years with sorafenib monotherapy in metastatic renal cell carcinoma: a case report
}

\author{
Kosuke Ueda*, Shigetaka Suekane, Naoyuki Ogasawara, Katsuaki Chikui, Shunsuke Suyama, Makoto Nakiri, \\ Kiyoaki Nishihara, Mitsunori Matsuo and Tsukasa Igawa
}

\begin{abstract}
Background: Molecular targeted therapies have dramatically improved the prognosis of metastatic renal cell carcinoma. However, patients in whom the treatment could initially be effective will experience disease progression later.

Case presentation: A 74-year-old Japanese man who was diagnosed with renal cell carcinoma with no evidence of metastasis presented to our hospital. He initially underwent radical nephrectomy, and subsequently the disease metastasized to the lung. Sorafenib was started for the lung metastases 1 year after the operation. The dose of sorafenib was reduced and temporarily discontinued because adverse events, including fatigue and cardiac infarction, occurred. The patient has continued sorafenib monotherapy for over 10 years without disease progression and severe adverse events.
\end{abstract}

Conclusions: We present a rare case of a patient with metastatic renal cell carcinoma who has survived for over 10 years while receiving sorafenib monotherapy.

Keywords: Renal cell carcinoma, Long-term response, Sorafenib, Monotherapy

\section{Background}

Renal cell carcinoma (RCC) accounts for $3 \%$ of adult malignancies and $90 \%$ of neoplasms arising from the kidney [1]. Approximately $20-40 \%$ of patients with initially localized disease who have had a nephrectomy will go on to develop metastases [2]. Patients with metastatic disease have a poor prognosis, with 5-year survival rates being less than $10 \%$ [2].

In recent years, targeted therapies have dramatically improved the prognosis of patients with metastatic RCC [3-6]. Some groups have demonstrated that there are several prognostic factors for metastatic RCC other than the Memorial Sloan Kettering Cancer Center (MSKCC) risk classification system, including serum $\mathrm{C}$-reactive protein level, metastasis status, and tumor shrinkage [7-10]. Previously, we reported that the duration of first-line treatment with molecular targeted therapies

\footnotetext{
* Correspondence: ueda_kousuke@med.kurume-u.ac.jp

Department of Urology, Kurume University School of Medicine, 67 Asahi-machi, Kurume 830-0011, Japan

is the strongest prognostic factor in patients with metastatic RCC [11]. In Japan, three types of tyrosine kinase inhibitors (TKIs), such as sorafenib, sunitinib, and pazopanib, and one type of mammalian target of rapamycin are applicable for patients with metastatic RCC as first-line molecular targeted therapy. However, there have been few reports of survival for over 10 years following treatment with only one molecular targeted agent. In this report, we present a case of a patient with metastatic RCC who has survived for over 10 years while receiving sorafenib monotherapy.

\section{Case presentation}

Our patient was a 74-year-old Japanese man who had been diagnosed with a left renal mass and no evidence of metastasis 11 years before presentation to our hospital. Left radical nephrectomy was performed. The histology of the renal tumor showed clear cell RCC, Fuhrman nuclear grade 2, which was classified as pathological stage T2bNOM0 according to TMN classification. Multiple 
pulmonary metastases were discovered 10 months after surgery. The patient was stratified as intermediate risk according to the MSKCC criteria. Although immunotherapy (interleukin-2 plus interferon) was started, disease progression was observed on a follow-up computed tomographic (CT) scan 6 months later (Fig. 1a).

Therefore, the patient was included in a phase II clinical trial and was started on treatment with oral sorafenib (Nexavar'; Bayer HealthCare Pharmaceuticals, Whippany, NJ, USA) $800 \mathrm{mg} /$ day 16 months after surgery. Three months after the initiation of sorafenib, a CT scan showed 19.3 \% regression based on the Response Evaluation Criteria in Solid Tumors. Then, after 1 year, 70.1 \% regression was observed (Fig. 1b). At this time, as grade 2 fatigue and grade 1 aspiration pneumonia emerged, the dose was reduced to $400 \mathrm{mg} /$ day. In addition, the patient twice had acute myocardial infarctions, one 4 years and one 5 years after initiation of sorafenib. Because general fatigue and weakness occurred, sorafenib treatment was stopped 5.5 years after initiation.

Progression of pulmonary metastases was observed 8 months after sorafenib treatment was stopped (Fig. 1c). Although we were reluctant to use a molecular targeted agent, we decided to prescribe sorafenib according to the strong wish of the patient. Treatment with sorafenib was restarted at $200 \mathrm{mg} /$ day. Because this dose was welltolerated without adverse events, sorafenib was increased to $400 \mathrm{mg} /$ day 5 months after had been restarted. The patient experienced grade 2 fatigue 7.5 years after initiation of sorafenib. Therefore, the schedule was changed to 3 days of treatment and 1 day of rest. The patient has continued sorafenib on this schedule without disease progression or severe adverse events (Fig. 1d).

\section{Discussion}

With the introduction of molecular targeted therapy, treatment of metastatic RCC has improved dramatically. Currently, molecular targeted agents are considered a standard first-line treatment for metastatic RCC. Sorafenib is an oral, multitargeted TKI that targets proliferation and angiogenesis by inhibiting vascular endothelial growth factor receptors $1-3$, platelet-derived growth factor receptor (PDGFR)- $\beta$, and Raf kinase [3, 12, 13]. In the TARGET study, the median progression-free survival (PFS) and overall survival (OS) of patients treated with sorafenib were 5.5 months and 17.8 months, respectively [3]. Some reports on Japanese patients showed that PFS ranged from 7.4 to 9 months $[14,15]$. Although molecular targeted agents such as sorafenib significantly prolong survival of patients with metastatic RCC compared with previous treatment, development of drug resistance is inevitable. Patients in whom treatment is initially effective will eventually experience disease progression. In our patient, cancer control has been achieved for over 10 years with sorafenib monotherapy. Because of adverse events such as fatigue and acute myocardial infarction, the patient temporarily discontinued the treatment. However, since disease progression was observed, the treatment with sorafenib was restarted in accordance with the patient's wishes.

This case shows long-term survival with use of sorafenib monotherapy. Several biomarkers have been studied as potential predictors of sorafenib response to improve patient selection. Kusuda et al. suggested that overexpression of PDGFR- $\alpha$ might be associated with resistance to sorafenib [16]. Jonasch et al. demonstrated that a high level of phosphorylated Akt was correlated with

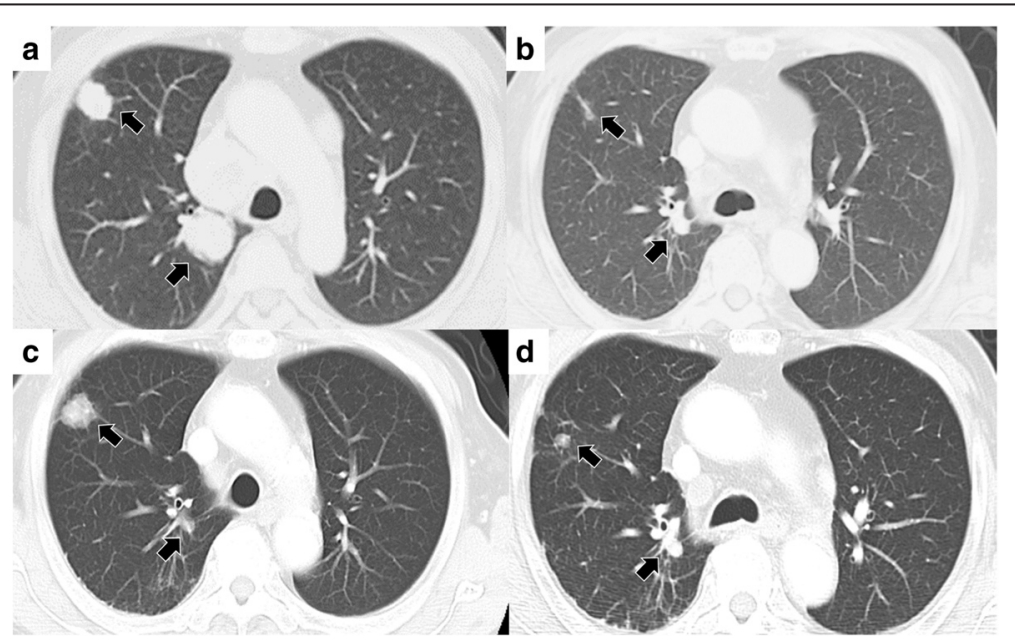

Fig. 1 a Computed tomographic scan taken before initiation of treatment with sorafenib reveals multiple pulmonary metastatic lesions (arrows). b Computed tomographic scan obtained 1 year after initiation of sorafenib reveals tumor regression (arrows) of $70.1 \%$ according to Response Evaluation Criteria in Solid Tumors. c Computed tomographic scan taken 8 months after sorafenib therapy was stopped reveals progression of pulmonary metastases (arrows). d Pulmonary metastases (arrows) remained stable 11 years after initiation of treatment with sorafenib 
inferior PFS and OS in patients treated with sorafenib [17]. In addition, Aziz et al. showed that microvessel area size was a predictor of sorafenib response [18]. These biomarkers were not examined in our patient. The utility of molecular biomarkers for predicting clinical outcomes with sorafenib therapy needs to be further studied.

About 3 months after starting and resuming sorafenib therapy, our patient experienced grade 2 fatigue. Also, myocardial infarction occurred twice during treatment with sorafenib. Previous reports suggest that cardiotoxicity is a rare adverse event in patients receiving sorafenib therapy $[3,19]$. Schmidinger et al. showed that $2.9 \%$ of patients treated with sorafenib experienced treatmentrelated fatal myocardial infarctions [20]. These events were controlled by dose reduction or discontinuation of sorafenib and symptomatic treatment by cardiologists. As there is the potential for occurrence of occlusion coronary artery disease during sorafenib treatment, patients should be carefully monitored for development of symptoms of cardiac infarction.

There is a question whether long-term treatment with molecular targeted agents increases the incidence of treatment-related adverse events. There are published data analyses of the long-term tolerability of sorafenib in clinical settings. In the phase III study of sorafenib, longterm treatment over approximately 3 years did not increase the overall incidence of treatment-related adverse events [21]. Furthermore, Porta et al. showed that longterm treatment with sunitinib did not increase new or more severe treatment-related toxicity [22]. They described how these agents could continue to have clinical benefit without untoward additional risk.

Currently, sequential treatment is strongly recommended for the management of metastatic RCC when disease progression or severe adverse events emerge. Guerin et al. reported a case of a patient with metastatic RCC of 14 years' duration who had a long-term response similar to our patient's following intermittent therapy with sorafenib [23]. Some researchers have also demonstrated that rechallenge with the same TKI could achieve a tumor response. Some patients with metastatic RCC retain sensitivity to monotherapy [24, 25]. Our present case report suggests that the possible response to sorafenib might be maintained for a long time in a sorafenib responder. In patients with metastatic RCC achieving a continuous response, it is important to continue first-line treatment including sorafenib as long as possible by managing adverse events.

\section{Conclusions}

We present a case of a patient with metastatic RCC with survival for over 10 years with use of sorafenib monotherapy. Biological predictive markers able to identify patients who can sustain durable stabilization of disease are desirable.

\section{Abbreviations}

CT, computed tomography; MSKCC, Memorial Sloan Kettering Cancer Center; OS, overall survival; PDGFR, platelet-derived growth factor receptor; PFS, progression-free survival; RCC, renal cell carcinoma; TKI, tyrosine kinase inhibitor

\section{Authors' contributions}

$\mathrm{KU}$ drafted the manuscript. SSue performed the clinical follow-up and contributed to the manuscript. NO, KC, SSuy, KN, and MM cared for the patient. MN and TI were responsible for the conception and design of the study, interpretation of the data, and critical revision of the manuscript. All authors read and approved the final manuscript.

\section{Competing interests}

The authors declare that they have no competing interests.

\section{Consent for publication}

Written informed consent was obtained from the patient for publication of this case report and any accompanying images. A copy of the written consent is available for review by the Editor-in-Chief of this journal.

Received: 16 December 2015 Accepted: 30 May 2016

Published online: 16 June 2016

\section{References}

1. Chow WH, Devesa SS, Warren JL, Fraumeni Jr JF. Rising incidence of renal cell cancer in the United States. JAMA. 1999;281:1628-31.

2. Motzer RJ, Bander NH, Nanus DM. Renal-cell carcinoma. N Engl J Med. 1996; 335:865-75

3. Escudier B, Eisen T, Stadler WM, Szczylik C, Oudard S, Siebels M, et al. Sorafenib in advanced clear-cell renal-cell carcinoma. N Engl J Med. 2007; 356:125-34

4. Hudes G, Carducci M, Tomczak P, Dutcher J, Figlin R, Kapoor A, et al. Temsirolimus, interferon alfa, or both for advanced renal-cell carcinoma. $\mathrm{N}$ Engl J Med. 2007;356:2271-81.

5. Motzer RJ, Hutson TE, Tomczak P, Michaelson MD, Bukowski RM, Rixe O, et al. Sunitinib versus interferon alfa in metastatic renal-cell carcinoma. $\mathrm{N}$ Engl J Med. 2007;356:115-24

6. Rini Bl, Escudier B, Tomczak P, Kaprin A, Szczylik C, Hutson TE, et al. Comparative effectiveness of axitinib versus sorafenib in advanced renal cell carcinoma (AXIS): a randomised phase 3 trial. Lancet. 2011;378:1931-9.

7. Yasuda Y, Saito K, Yuasa T, Kitsukawa S, Urakami S, Yamamoto S, et al. Prognostic impact of pretreatment $C$-reactive protein for patients with metastatic renal cell carcinoma treated with tyrosine kinase inhibitors. Int J Clin Oncol. 2013;18:884-9.

8. Patil S, Figlin RA, Hutson TE, Michaelson MD, Negrier S, Kim ST, et al Prognostic factors for progression-free and overall survival with sunitinib targeted therapy and with cytokine as first-line therapy in patients with metastatic renal cell carcinoma. Ann Oncol. 2011;22:295-300.

9. Beuselinck B, Oudard S, Rixe O, Wolter P, Blesius A, Ayllon J, et al. Negative impact of bone metastasis on outcome in clear-cell renal cell carcinoma treated with sunitinib. Ann Oncol. 2011;22:794-800.

10. Seidel C, Busch J, Weikert S, Steffens S, Bokemeyer C, Grunwald V. Tumour shrinkage measured with first treatment evaluation under VEGF-targeted therapy as prognostic marker in metastatic renal cell carcinoma (mRCC). Br J Cancer. 2013;109:2998-3004.

11. Ueda K, Suekane S, Nishihara K, Ogasawara N, Kurose H, Hayashi S, et al. Duration of first-line treatment with molecular targeted-therapy is a prognostic factor in metastatic renal cell carcinoma. Anticancer Res. 2015;35:3415-21.

12. Ratain MJ, Eisen T, Stadler WM, Flaherty KT, Kaye SB, Rosner GL, et al. Phase II placebo-controlled randomized discontinuation trial of sorafenib in patients with metastatic renal cell carcinoma. J Clin Oncol. 2006;24:2505-12.

13. Rini BI. Vascular endothelial growth factor-targeted therapy in metastatic renal cell carcinoma. Cancer. 2009;115:2306-12.

14. Akaza H, Tsukamoto T, Murai M, Nakajima K, Naito S. Phase II study to investigate the efficacy, safety, and pharmacokinetics of sorafenib in Japanese patients with advanced renal cell carcinoma. Jpn J Clin Oncol. 2007;37:755-62.

15. Tanigawa G, Kawashima A, Yamaguchi S, Nishimura K, Miyoshi S, Kajikawa J, et al. Clinical outcome and prognostic factors of sorafenib in Japanese 
patients with advanced renal cell carcinoma in general clinical practice. Jpn J Clin Oncol. 2011;41:1265-70.

16. Kusuda Y, Miyake H, Behnsawy HM, Fukuhara T, Inoue TA, Fujisawa M. Prognostic prediction in patients with metastatic renal cell carcinoma treated with sorafenib based on expression levels of potential molecular markers in radical nephrectomy specimens. Urol Oncol. 2013;31:42-50.

17. Jonasch E, Corn P, Pagliaro LC, Warneke CL, Johnson MM, Tamboli P, et al. Upfront, randomized, phase 2 trial of sorafenib versus sorafenib and low-dose interferon alfa in patients with advanced renal cell carcinoma: clinical and biomarker analysis. Cancer. 2010;116:57-65.

18. Aziz SA, Sznol JA, Albiges L, Zito C, Jilaveanu LB, Camp RL, et al. Microvessel area as a predictor of sorafenib response in metastatic renal cell carcinoma. Cancer Cell Int. 2014;14:4.

19. Stadler WM, Figlin RA, McDermott DF, Dutcher JP, Knox JJ, Miller Jr WH, et al. Safety and efficacy results of the advanced renal cell carcinoma sorafenib expanded access program in North America. Cancer. 2010;116: 1272-80.

20. Schmidinger M, Zielinski CC, Vogl UM, Bojic A, Bojic M, Schukro C, et al. Cardiac toxicity of sunitinib and sorafenib in patients with metastatic renal cell carcinoma. J Clin Oncol. 2008;26:5204-12.

21. Naito S, Tsukamoto T, Murai M, Fukino K, Akaza H. Overall survival and good tolerability of long-term use of sorafenib after cytokine treatment: final results of a phase II trial of sorafenib in Japanese patients with metastatic renal cell carcinoma. BJU Int. 2011;108:1813-9.

22. Porta C, Gore ME, Rini BI, Escudier B, Hariharan S, Charles LP, et al. Long-term safety of sunitinib in metastatic renal cell carcinoma. Eur Urol. 2016;69:345-51.

23. Guerin M, Salem N, Walz J, Dermeche S, Gravis G. Major response with sorafenib in advanced renal cell carcinoma after 14 years of follow-up. World J Surg Oncol. 2013;11:243.

24. Nozawa M, Yamamoto Y, Minami T, Shimizu N, Hatanaka Y, Tsuji H, et al. Sorafenib rechallenge in patients with metastatic renal cell carcinoma. BJU Int. 2012:110:E228-34.

25. Zama IN, Hutson TE, Elson P, Cleary JM, Choueiri TK, Heng DY, et al. Sunitinib rechallenge in metastatic renal cell carcinoma patients. Cancer. 2010;116:5400-6.

\section{Submit your next manuscript to BioMed Central and we will help you at every step:}

- We accept pre-submission inquiries

- Our selector tool helps you to find the most relevant journal

- We provide round the clock customer support

- Convenient online submission

- Thorough peer review

- Inclusion in PubMed and all major indexing services

- Maximum visibility for your research

Submit your manuscript at www.biomedcentral.com/submit

) Biomed Central 